\title{
D-Risk: a decision-support webtool for improving drought risk management in irrigated agriculture
}

\author{
David Haro-Monteagudo ${ }^{1,2}$, Jerry W. Knox ${ }^{1}$ and Ian P. Holman ${ }^{1}{ }^{*}$ \\ ${ }^{I}$ Cranfield Water Science Institute, Cranfield University, Bedfordshire MK43 OAL, UK \\ ${ }^{2}$ Estación Experimental de Aula Dei - Centro Superior de Investigaciones Científicas (EEAD - CSIC) \\ Avda Montanana 1005, 50059 Zaragoza, Spain
}

*Corresponding author: i.holman@cranfield.ac.uk

\begin{abstract}
Drought constitutes a significant production and business risk in agriculture, particularly for those enterprises dependent on irrigation to deliver high quality continuous supplies of fresh produce to the retail sector. Whilst most farmers are well attuned to managing short term weather-related crop risks, they lack access to tools that can support medium-term decision-making and risk management strategies under conditions of increasing water scarcity and climate uncertainty. This paper describes D-Risk, an intuitive online webtool designed to help farming enterprises easily understand their existing and emergent drought and irrigation abstraction risks and thereby support more robust decision-making regarding future changes in crop planning and water resources infrastructure investment.
\end{abstract}

\section{Highlights}

- Lack of tools to support farm level drought risk planning

- D-Risk is a free, multi-platform, webtool (www.d-risk.eu)

- Probabilistic assessment of irrigation deficit and licence usage

Keywords: irrigation; reservoir; water resources; probabilistic; risk.

\section{Software availability}


Software name: D-Risk

Year first available: 2018

Development team: Mick Redman, David Haro-Monteagudo, Jerry Knox and Ian Holman

Software required: web browser using JavaScript (Google Chrome v11+; Opera v15+; Firefox v4+; IE v9+) with window width at $>1200 p x$

Availability: webtool and documentation are freely accessible at www.d-risk.eu

\section{Introduction}

Agriculture is widely regarded as the sector most influenced by short and longer-term weather fluctuations. Drought is an important abiotic stress on crop productivity and increasingly a major business risk not only in arid countries (Wilhite, 2007) but also in temperate and humid regions (Knox et al., 2010). Although the UK is typically considered a 'wet' region in terms of food production, agribusinesses involved in high-value agricultural and horticultural production are not immune to the effects of drought, since contract conditions stipulate the delivery (timing and volume) and quality assurance attributes of produce supplied to processors and retailers (Rey et al. 2016).

Irrigation to buffer short-term periods of insufficient rainfall (supplemental irrigation) is thus an essential component of UK production. Irrigation investment is driven by the need to maximise both yield and quality - most crops that are irrigated generate substantial financial benefits (Rey et al., 2016; Morris et al., 2017) but are sensitive to short periods of water deficit or drought stress, particularly when these coincide with critical growth stages.

Farmers typically manage drought risks through planning of cropping and anticipated irrigation demand, taking account of their fixed allowable volumes defined within their annual abstraction licences (permits). Most businesses allow for a certain level of precautionary 'headroom' defined as the difference between their licensed volume and expected volumetric irrigation demand in a design 'dry' year (typically the $80 \%$ probability of non-exceedence). Increasing concerns regarding future 
access to water supplies for agriculture (Knox et al., 2018), coupled with increased risks from climate change and new environmental regulation mean farm businesses need to evaluate the reliability of their irrigation licences and adapt their business plans to achieve acceptable levels of drought risk (Rey et al., 2018).

Whilst numerous tools and decision support systems exist for irrigation, these have focused on in-field crop management and precision irrigation (Navarro-Hellín et al., 2016), system-level canal irrigation management (Wang et al., 2017) or regional level assessments of water supply and demand to assess constraints on productivity (Winter et al., 2017). There are no known tools available to support individual farming enterprises in understanding and assessing their business-level drought and abstraction risks. This paper describes the free, multi-platform (PC, laptop and tablet) D-Risk webtool (www.d-risk.eu). D-Risk has been iteratively co-designed, in collaboration with stakeholders, to help farm businesses understand their complex abstraction and drought-related risks to support informed decision making regarding crop planning and on-farm water resources infrastructure investment.

\section{D-Risk webtool development}

In summary, D-Risk combines a national-scale synthetic climatology database with location-specific farm data to evaluate current drought risks (Figure 1). Using a dataset of multiple (100) gridded synthetic equally-probable baseline weather series, an agroclimatic index (annual maximum potential soil moisture deficit or $\mathrm{PSMD}_{\max }$ ) is derived for a given site. This index correlates well with irrigation demand (de Silva et al., 2007; Rodriguez-Diaz et al., 2007). Farm-scale theoretical irrigation need (annual and monthly) is estimated using crop- and soil- specific linear regressions between irrigation need and PSMD ${ }_{\max }$ (Knox et al., 1997). These regressions are accepted by the water regulatory agency in setting volumetric limits on abstraction licences. Theoretical irrigation demand and monthly abstraction (supply) are then modelled to develop cumulative distribution functions and uncertainty envelopes for two risk metrics relating to the inability to meet irrigation need and having an insufficient license volume. Finally, the user can explore 'what if' scenarios to assess the impacts of changing cropping (mix and area), storage availability and licence conditions and evaluate the consequences on their drought risk profile. A brief description of each stage is given below. 


\section{Weather database}

Given their high degree of spatial variability, potentially long duration and multi-variate nature of droughts, observed historical weather data are insufficient to adequately characterise and capture the full range of potential drought events required to develop a risk-based approach. D-Risk therefore uses a large dataset of multiple equally-probable synthetic weather time series termed the "MaRIUS event set" (Guillod et al. 2017; 2018) which were generated using the weather@home2 distributed climate modelling experiment (Guillod et al. 2017). This is based on the HadAM3P Global Circulation Model, downscaled with the HadRM3P Regional Climate Model (RCM) from the UK Met Office Hadley Centre (Gordon et al., 2000). The dataset consists of 100 bias-corrected high resolution $25 \mathrm{~km}$ gridded RCM weather sequences for the UK that has been shown to produce a good representation of extreme weather events (Guillod et al., 2017).

\section{Farm level input data}

D-Risk was developed to be intuitive, quick and simple to use, so limited farm data are required. The postcode is required to extract local weather data from the gridded "MaRIUS event set" climatology for the grid cell in which the postcode centroid falls. For each crop type (from a list of 16 options), the soil type (based on three classes of available water capacity matching those used by agronomists providing irrigation scheduling advice), planting month and irrigated area are defined. For each abstraction licence held by the farm, the source (surface or groundwater), purpose (direct abstraction or storage), abstraction limits (annual, daily) and period during which water can be abstracted (start and end dates), are required. Finally, total 'live' on-farm reservoir storage (if applicable) is entered.

\section{Modelling irrigation demand}

Previous research demonstrated a strong relationship between irrigation need (depth applied) and $\mathrm{PSMD}_{\max }$ (Knox et al., 1997). Annual PSMD ${ }_{\max }$ was calculated using monthly rainfall and reference evapotranspiration (ETo) data from the MaRIUS event set: 


$$
\operatorname{PSMD}_{(t)}=\operatorname{Max}\left[0, P S M D_{(t-1)}+E T_{0(t)}-P_{(t)}\right]
$$

Where $\operatorname{PSMD}_{(\mathrm{t})}$ is the deficit at the end of month $t(\mathrm{~mm}), \operatorname{PSMD}_{(\mathrm{t}-1)}$ is the deficit at the end of month $t$ $l(\mathrm{~mm}), \mathrm{ET}_{0(\mathrm{t})}$ is reference evapotranspiration in month $t(\mathrm{~mm})$ and $\mathrm{P}_{(\mathrm{t})}$ is rainfall in month $t(\mathrm{~mm})$. The PSMD is reset to zero at the end of each year, as winter rainfall generally exceeds $\mathrm{ET}_{\mathrm{o}}$ in the UK allowing soils to return to field capacity (albeit for only a short period during multi-year droughts). The theoretical irrigation need for each crop in each year in the 100 thirty-year weather series for the baseline (1975-2004) are calculated using the linear regression equations by combining the farm reported crop and soil data with the $\mathrm{PSMD}_{\max }$ data. The user can modify the 'theoretical' irrigation needs to reflect their experience, for example, due to varietal crop differences or assumptions regarding application efficiency or irrigation technology. Total annual volumetric demand is calculated by summing the volumetric irrigation need for each crop. It is disaggregated into a monthly distribution and input into a water balance model to assess how the irrigation demand compares against water availability, taking into account abstraction licence constraints and on-farm water storage availability. D-Risk assumes surface water sources are used first, and then groundwater, due to the greater vulnerability of surface water to restrictions during hydrological drought, although D-Risk currently does not represent the likelihood of such abstraction restrictions. Similarly, irrigation from direct abstraction is prioritised before reservoir water, reflecting normal practice to save stored water for periods when flow constraints are imposed on direct abstraction.

Due to abstraction being only possible during the defined licence period, the irrigation supply $I S_{l, t}$ from direct spray irrigation licence $l \in D L$, where $D L$ represents the total number of direct spray irrigation licences defined for the farm is: 


$$
\begin{aligned}
& I S_{l, t}=\min \left(I D_{t}-\sum_{i=1}^{l-1} I S_{i, t}, \text { ndays }_{t} \cdot \text { daily limit }_{l}, \text { annual limit }_{l}\right. \\
& \left.-\sum_{j=\text { start month }}^{t-1} I S_{l, j}\right)
\end{aligned}
$$

Where $I D_{t}$ is the total irrigation demand in month $t$; ndays $s_{t}$ is the number of days in month $t$; daily limit $_{l}$ and annual limit ${ }_{l}$ are the maximum daily and annual abstraction from licence $l$ respectively; and start month $h_{l}$ is the first allowed abstraction month defined for licence $l$. For a farm with multiple abstraction licences for direct spray irrigation, if abstraction licence $l$ is not sufficient to meet demand $I D_{t}$, equation (2) is applied recursively until all available licences have been used. The process is repeated until demand in that month is met or the monthly abstraction limit defined by ndays $_{t} \cdot$ daily limit $_{l}$ for all the defined direct abstraction licences is reached.

Where storage has been defined, if demand $I D_{t}$ was not fully met from direct abstraction, then storage irrigation supply $\operatorname{SIS}_{t}$ will be:

$$
S I S_{t}=\min \left(I D_{t}-\sum_{i=1}^{D L} I S_{i, t}, V_{t-1}\right)
$$

Where $V_{t-1}$ corresponds to the volume of live storage water at the end of the previous month. Reservoir losses (from evaporation and seepage) are assumed to be negligible. The volume at the end of month $t$ is updated as $V_{t}=V_{t-1}-S I S_{t}$, and the water necessary to fill the reservoir back to maximum is defined as $S D_{t}=V_{\max }-V_{t}$. As with irrigation demand, the supply from storage licence $s$ in month $t S S_{s, t}$ to meet $S D_{t}$ needs to be abstracted from storage licence $s \in S L$, where $S L$ represents the total number of storage licences defined for the farm and calculated as: 


$$
\begin{gathered}
S S_{S, t}=\min \left(S D_{t}-\sum_{i=1}^{S-1} S S_{i, t}, \text { ndays }_{t} \cdot \text { daily limit }_{s}, \text { annual limit }_{s}\right. \\
\left.-\sum_{j=\text { start month }} S S_{S, j}\right)
\end{gathered}
$$

For a farm with multiple abstraction licences for storage, if abstraction licence $s$ is not sufficient to supply demand $S D_{t}$, equation (4) is applied recursively until all the available licences have been used. The process is repeated until demand in that month is fulfilled or the monthly abstraction limit defined by ndays $_{t} \cdot$ daily limit $_{s}$ for all the defined storage abstraction licences is reached.

\section{Risk metrics}

In particularly dry years, seasonal irrigation demands will exceed the total licensed volume and available storage, leading to an irrigation deficit with consequent impacts on crop yield, quality and revenue. Under these circumstances, typical practice is to prioritise crops with the highest returns to irrigation, abandon some crops and/or partially irrigate other crops. While reservoir storage can help mitigate the impact of an irrigation deficit, it may not be sufficient in an exceptionally dry year or during multi-year droughts.

Using the outputs from the water balance modelling, D-Risk derives annual time-series for two metrics, (i) irrigation deficit, calculated as the volumetric demand not met either due to abstraction limits and/or insufficient available reservoir storage (Equation 5), and (ii) aggregate licensed 'headroom', calculated as the combined annual volume of all licences (direct and storage) not used in any given year (Equation 6). When headroom is zero, a business has reached its licensed limit and cannot abstract additional water for irrigation or refilling a reservoir within the year.

$$
\text { Irrigation Deficit }=\sum_{t=1}^{12}\left(I D_{t}-\sum_{l=1}^{D L} I S_{l, t}-S I S_{t}\right)
$$




$$
\text { Headroom }=\sum_{i=1}^{D L} \text { annual limit }_{i}+\sum_{j=1}^{S L} \text { annual limit }_{j}-\sum_{t=1}^{12}\left(\sum_{i=1}^{D L} I S_{i, t}+\sum_{j=1}^{S L} S S_{j, t}\right)
$$

Where $I D_{t}$ is the total irrigation demand in month $t ; I S_{t, l}$ is the irrigation supply from direct spray irrigation licence $l$ in month $t$; SIS $S_{t}$ is the irrigation supply from storage in month $t ; S S_{s, t}$ is the supply to the reservoir from storage licence $s$ in month $t$; and $D L$ and $S L$ are the total number of direct and storage licences respectively defined by the user.

D-Risk expresses the two risk metric outputs as annual cumulative probability functions (CDF) for exceeding a given level of irrigation deficit or headroom, assuming that the future probability or likelihood is equally based on all years within all 100 modelled time series. In addition, the best and worst series within the 100 equi-probable baseline series are also represented as an uncertainty envelope.

Finally, it is important to recognise that the modelled irrigation needs at both the farm and field level represent 'net' requirements. Most UK irrigation is from overhead systems supplied via underground pipes, so conveyance losses are very small. In contrast to international irrigation, UK farmers typically ignore in-field losses and non-uniformity when scheduling, implicitly accepting some under-irrigation. Under this assumption, gross and net in-field irrigation needs are identical.

\section{D-Risk application}

The D-Risk webtool enables farmers to understand their current or 'baseline' level of drought risk and then to conduct various 'what if' analyses to assess the consequences of farm business adaptation to drought risk. These could include, for example, evaluating the consequences of reducing their overall irrigated area (reducing irrigation command), modifying planting programmes and crop mix (changing the agronomic need for irrigation in a dry year), changing irrigation schedules (prioritising which crops should be irrigated) or investing in on-farm reservoir storage (to increase total resource availability and reliability and/or support business expansion plans). 
Many farmers are also acutely aware that their current annual licensed allocation and 'headroom' are at risk, as the government implement major legislative reforms to the abstraction licensing regime to reduce levels of over-abstraction and restore environmental flows. D-Risk can support farm businesses in understanding how potential reductions in licensed allocation and 'headroom' might impact on their future cropping programmes.

Example case study applications are provided on the D-Risk website (http://www.drisk.eu/index.php?params=casestudies) which highlight important decisions farmers often need to make in reconciling their irrigation deficits and licensed headroom challenges. It thus provides utility in understanding both drought risks and the reliability of existing sources of supply. Future planned enhancements to D-Risk include incorporating a reservoir module to enable users to evaluate options for optimising additional storage (capacity) and their indicative cost.

\section{Conclusions}

Through a co-design process with end users, the D-Risk webtool with its visual simplicity in representing complex drought risk metrics has advanced farm-level understanding of drought risk to support development of more resilient drought plans for the UK agricultural sector. Future development of D-Risk will seek to incorporate the risks of mandatory surface water abstraction restrictions during extreme droughts, so that the risk metrics also reflect the reliability of a water source. Although D-Risk was developed specifically for the UK irrigated farming sector, the modelling approach and software interface could have widespread utility in other countries where irrigation is an important component of water use and where drought risks, rainfall uncertainty and water competition and scarcity are threats to the rural economy.

\section{Acknowledgement}

The authors acknowledge funding support from UK Research and Innovation (UKRI) NERC innovation grant (NE/N017471/1) and access to the MaRIUS event sets (NE/L010364/1, NE/L010208/1, NE/L010399/1, NE/L010186/1). We acknowledge support from Melvyn Kay (UK Irrigation Association), Paul Hammett (National Farmers Union), Tim Jolly (WO \& PO Jolly), 
Andrew Blenkiron (Euston Estate), Lindsay Hargreaves (Frederick Hiam Ltd), and Andrew Francis (Elveden) in co-design and testing, and website development by Mick Redman. The supporting annual PSMDmax data referred to in this article can be accessed at https://doi.org/10.17862/cranfield.rd.6792260. The_MaRIUS event set data are available on the Centre for Environmental Data Analysis (CEDA) platform (see https://doi.org/10.5285/0cea8d7aca57427fae92241348ae9b03). 
Figure 1 Schematic showing the inputs, outputs and risk metrics developed for the D-Risk webtool.

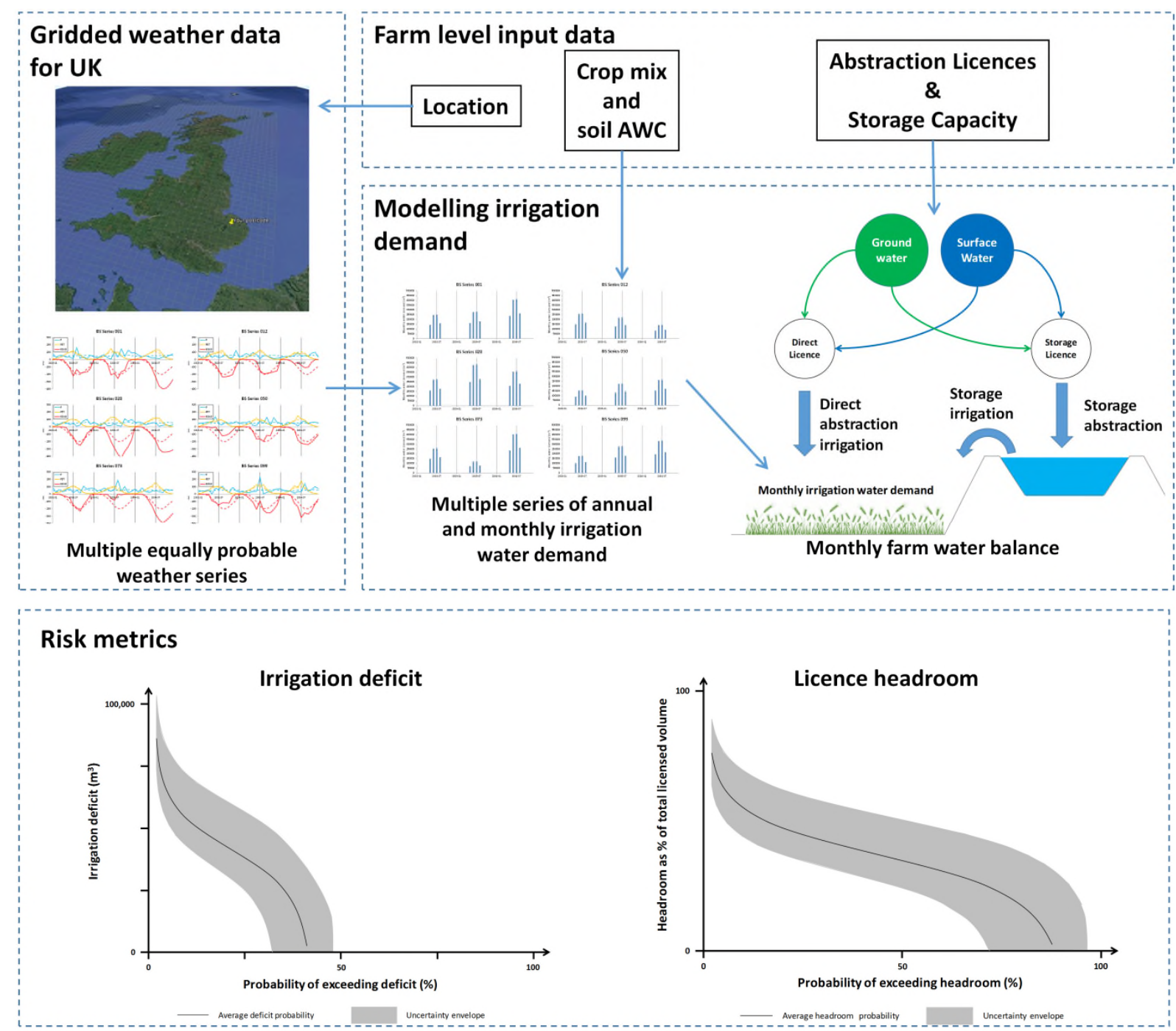

\section{References}

de Silva, C.S., Weatherhead, E.K., Knox, J.W., Rodriguez-Diaz, J.A (2007). Mapping the climate change impacts on irrigation water requirements for Maha season paddy rice in Sri Lanka. Agricultural Water Management 93: 19-29.

Gordon, C., Cooper, C., Senior, C.A., Banks, H., Gregory, J.M., Johns, T.C., Mitchell, J.F.B., Wood, R.A. (2000). The simulation of SST, sea ice extents and ocean heat transports in a version of the Hadley Centre coupled model without flux adjustments. Climate Dynamics 16(2-3): 147168. 
Guillod, BP.; Jones, RG.; Dadson, SJ, Coxon G, Bussi G, Freer J, Kay AL, Massey NR, Sparrow SN, Wallom DCH, Allen MR, Hall JW (2018) A large set of potential past, present and future hydro-meteorological time series for the UK. Hydrol Earth Syst Sci 22(1): 611-634.

Guillod, B.P., Jones, R.G., Bowery, A., Haustein, K., Massey, N.R., Mitchell, D.M., Otto, F.E. L., Sparrow, S.N., Uhe, P., Wallom, D.C.H., Wilson, S., and Allen, M.R. (2017) weather@home 2: validation of an improved global-regional climate modelling system, Geoscientific Model Development 10: 1849-1872.

Knox, J.W., Weatherhead, E.K., Bradley, R.I. (1997). Mapping the total volumetric irrigation water requirements in England and Wales. Agricultural Water Management 33: 1-19.

Knox, J., Morris, J.W., Hess, T.M. (2010). Identifying future risks to UK agricultural crop production: Putting climate change in context. Outlook on Agriculture 39(4): 249-256.

Knox, J.W., Haro-Monteagudo, D., Hess, T.M., and Morris, J (2018). Identifying trade-offs and reconciling competing demands for water - integrating agriculture into a robust decisionmaking framework. Earth's Future http://dx.doi.org/10.1002/2017EF000741.

Morris J, El Chami D, Daccache, A., Else, M and Knox J.W (2017) Essential irrigation and the value of water for strawberries in a humid climate. Agricultural Water Management https://doi.org/10.1016/j.agwat.2017.09.004.

Navarro-Hellín, H, Martínez-del-Rincon, J., Domingo-Miguel, R., Soto-Valles, F., Torres-Sánchez, R. (2016) A decision support system for managing irrigation in agriculture Computers and Electronics in Agriculture 124: 121-131.

Rey, D., Holman, I.P., Daccache, A., Morris, J., Weatherhead, E.K., and Knox, J.W. (2016). Modelling and mapping the economic value of supplemental irrigation in a humid climate. Agricultural Water Management 173: 13-22.

Rey, D., Holman, I.P., Knox, J.W., 2017. Developing drought resilience in irrigated agriculture in the face of increasing water scarcity. Regional Environmental Change 17(5): 1527-1540.

Rodriguez-Diaz, J.A., Weatherhead, E.K., Knox, J.W., Camacho, E. (2007). Climate change impacts on irrigation water requirements in the Guadalquivir River Basin in Spain. Regional Environmental Change 7(3): 149-159. 
Wang, W., Cui, Y., Luo, Y., Li, Z., Tan, J. (2017) Web-based decision support system for canal irrigation management Computers and Electronics in Agriculture https://doi.org/10.1016/j.compag.2017.11.018.

Wilhite D. (2007). Preparedness and coping strategies for agricultural drought risk management: recent progress and trends. In: Sivakumar M.V.K. and Motha R.P. (eds.). Managing Weather and Climate Risks in Agriculture. Springer, pp. 21-38.

Winter, J.M., Young, C.A., Mehta, V.K., Ruane, A.C., Azarderakhsh, M., Davitt, A., McDonald, K., Haden, V.R., Rosenzweig, C (2017) Integrating water supply constraints into irrigated agricultural simulations of California. Environmental Modelling and Software 96: 335-346. 